\title{
Sorption removal of arsenic by cerium-exchanged zeolite $P$
}

\begin{abstract}
Modification of zeolite $\mathrm{P}$ was performed by exchanged of its sodium with cerium(III). The resulting cerium-exchanged zeolite $\mathrm{P},(\mathrm{CeZP})$ did not change in its crystallinity compared to original zeolite. The CeZP was subsequently used to sorb $\mathrm{As}(\mathrm{V})$ from aqueous solution. Maximum sorption of $\mathrm{As}(\mathrm{V})$ by CeZP occurred at $\mathrm{pH}$ range 3ï 10. In addition, the sorption capacity increased with increasing initial $\mathrm{As}(\mathrm{V})$ concentrations. The sorption follows Langmuir model with maximum sorption capacity of $8.72 \mathrm{mg}$ gi 1 at $25^{\circ} \mathrm{C}$ and increased to $23.42 \mathrm{mg}$ gi 1 at $90^{\circ} \mathrm{C}$, indicating an endothermic process. The arsenic sorption by CeZP was not affected by the present of nitrate, chloride, sulphate, carbonate and bromide but was reduced significantly in the presence of phosphate. This study shows that the as prepared CeZP was found effective for the removal of arsenic from wastewater sample of wood treatment industry.
\end{abstract}

Keyword: Ce-exchanged zeolite; Arsenate sorption; Langmuir isotherm; Wasterwater 